\title{
El VIAJE DE UNA IMAGEN. UNA COPIA DE LA ÚlTiMA CENA DEL ORATORIO Gonfalone de Roma en la iglesia del Salvador de Teruel
}

The journey of an image. A copy of the Last Supper of the Gonfalone oratory in Rome in the church of Salvador of Teruel

\section{Pedro Luis Hernando Sebastián ${ }^{1}$}

Recibido: 5-6-2021

Aceptado: 7-9-2021

\section{Resumen}

En el Museo de Arte Sacro de Teruel se conserva una pintura sobre tabla con la escena de la Sagrada Cena. Con el presente trabajo pretendemos estudiar su relación con el Oratorio del Gonfalone de Roma y demostrar que, gracias a la generalización de la producción de estampas y grabados, este territorio pudo acceder a las mejores obras de arte e incorporarse a las rutas de comunicación artística del momento.

Palabras clave: iconografí, grabados, siglo XVII, Teruel, Agresti.

\section{Abstract}

In the Museum of Sacred Art of Teruel there is a painting on panel with the scene of the Sacred Supper. With this work we intend to study its relationship with the Oratory of the Gonfalone in Rome. Also, to demonstrate that, thanks to the generalization of the production of prints and engravings, this territory was able to access the best works of art and to join the routes of artistic communication of the period.

Keywords: iconography, engravings, $17^{\text {th }}$ century, Teruel, Agresti. 


\section{Descripción}

Aunque de origen medieval, la iglesia del Salvador de Teruel es un edificio realizado a finales del siglo XVII. Se reconstruyó tras su hundimiento el 26 de mayo de 1667, presentando su actual estado el 14 de agosto del año 1682, día en que se bendijo la nueva iglesia (Polo Rubio 2005, p. 214). Es un edificio sencillo, pero que atesora uno de las obras devocionales más significativas de la ciudad, el Cristo de las tres manos, motivo por el cual ha sido objeto de especial atención por parte de la sociedad turolense en lo que se refiere a su dotación artística y religiosa.

En ese contexto podemos ubicar la obra, de hacia 1600, objeto de estudio. Se trata de la puerta de fondo del expositor del retablo mayor del siglo XVIII de dicha iglesia. La cara exterior representa la escena de la Última Cena de Jesús con sus discípulos (Fig. 1). El protagonismo corresponde a la imagen de Cristo, que sostiene la Sagrada Forma con su mano derecha. A simple vista, identificamos sin problema a san Juan, caracterizado por su juventud, a Judas, en primer plano, mirando al espectador mientras sujeta la bolsa de monedas entregadas por su traición, y a san Pedro. También al copero san Marcial, que aparece a nuestra izquierda, portando una bandeja. Hay que señalar que únicamente aparecen nueve apóstoles, quizá por la necesidad de adaptarse al formato vertical de la tabla. Sirviendo como fondo de la representación aparece una escalinata flanqueada por columnas salomónicas, entre las cuales se desarrolla la escena del Lavatorio de pies. El reverso presenta decoración de rocalla de similar factura que la del interior del tabernáculo (Fig. 2).

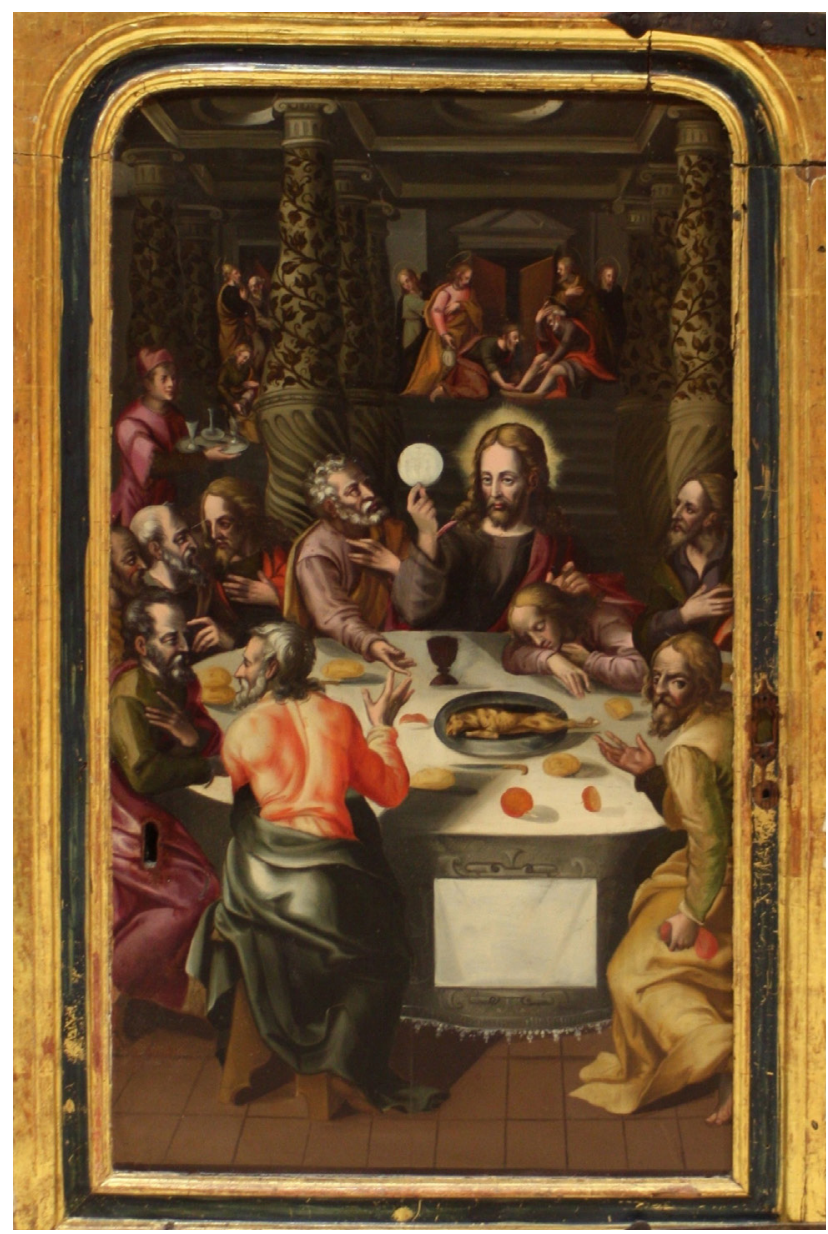

Fig. I. Tabla de la Última Cena. Museo de Arte Sacro, Teruel. Foto: Pedro Luis Hernando.

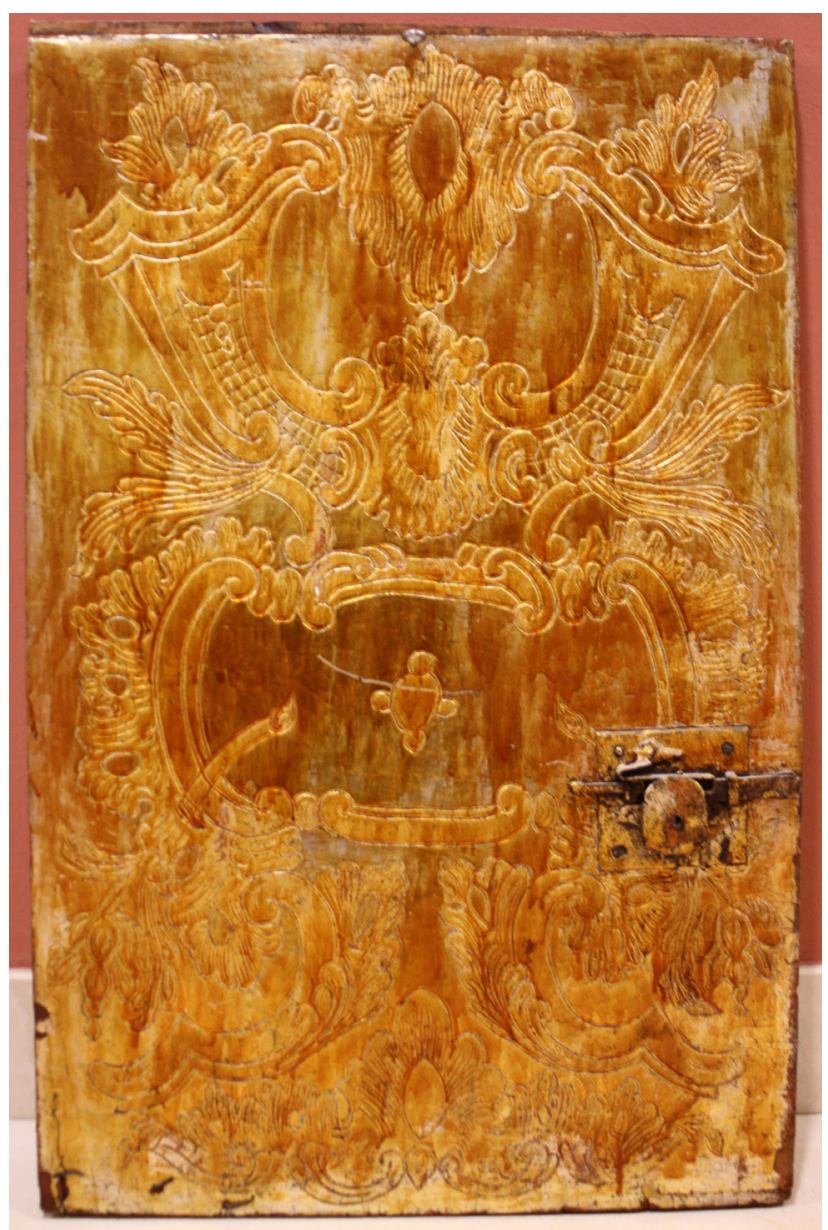

Fig. 2. Decoración del reverso de la tabla de la Última Cena. Museo de Arte Sacro, Teruel. Foto: Pedro Luis Hernando. 
La primera referencia localizada de la tabla procede del inventario artístico de Teruel y su provincia realizado por Santiago Sebastián, quien la data en los últimos años del siglo XVI (Sebastián, 1974)². El mismo autor fecha el retablo en el que se ubica en torno al año 1730. La obra no presenta ningún otro tipo de referencia, y al tratarse de la pieza perteneciente a una obra mayor, la escasa documentación existente tampoco tiene por qué hacer una alusión específica a su existencia.

$\mathrm{Su}$ formato es de 82 por 48 centímetros y presenta un buen estado de conservación, no existiendo más intervención documentada que la del tratamiento de limpieza que se realizó previamente a su traslado al Museo de Arte Sacro de Teruel inaugurado en el año 1984. No obstante, existen varias evidencias que hacen pensar que la tabla ha sido objeto de modificaciones que pudieron afectar a su apariencia original.

En primer lugar, la diferencia de cronología entre la tabla y el retablo ya nos indica una reutilización de la misma. En segundo lugar, la existencia de dos cerraduras similares, una a cada lado de la tabla, indica un cambio en el sentido de apertura. En efecto, en el inédito inventario de patrimonio artístico diocesano, realizado en los años 70, el redactor de la ficha apunta la posibilidad de que se trate de la puerta del sagrario de otro retablo. En tercer lugar, no queremos obviar que la circunstancia citada, de que sólo aparezcan nueve apóstoles en la escena, pueda ser debida a que una sección de la tabla fuera cortada para acomodarla al espacio de una nueva mazonería. Finalmente, la decoración de rocalla dorada del interior de la tabla oculta completamente las señales de la cerradura primitiva, signo inequívoco de que esta se aplicó con posterioridad, quizás para acomodarla al nuevo retablo del siglo XVIII.

Al retirar la tabla para trasladarla al museo, quedó en el retablo una parte de la decoración que la rodeaba. Se trata de una pintura sobre lienzo adherida a la madera del retablo. Tiene forma de portada con dos columnas salomónicas a los lados y una inscripción en la parte superior alusiva a la sangre derramada por Cristo para la salvación de los hombres (Fig. 3). Nos parece de buena factura y que formaría un conjunto con la tabla estudiada, pero introduce otra

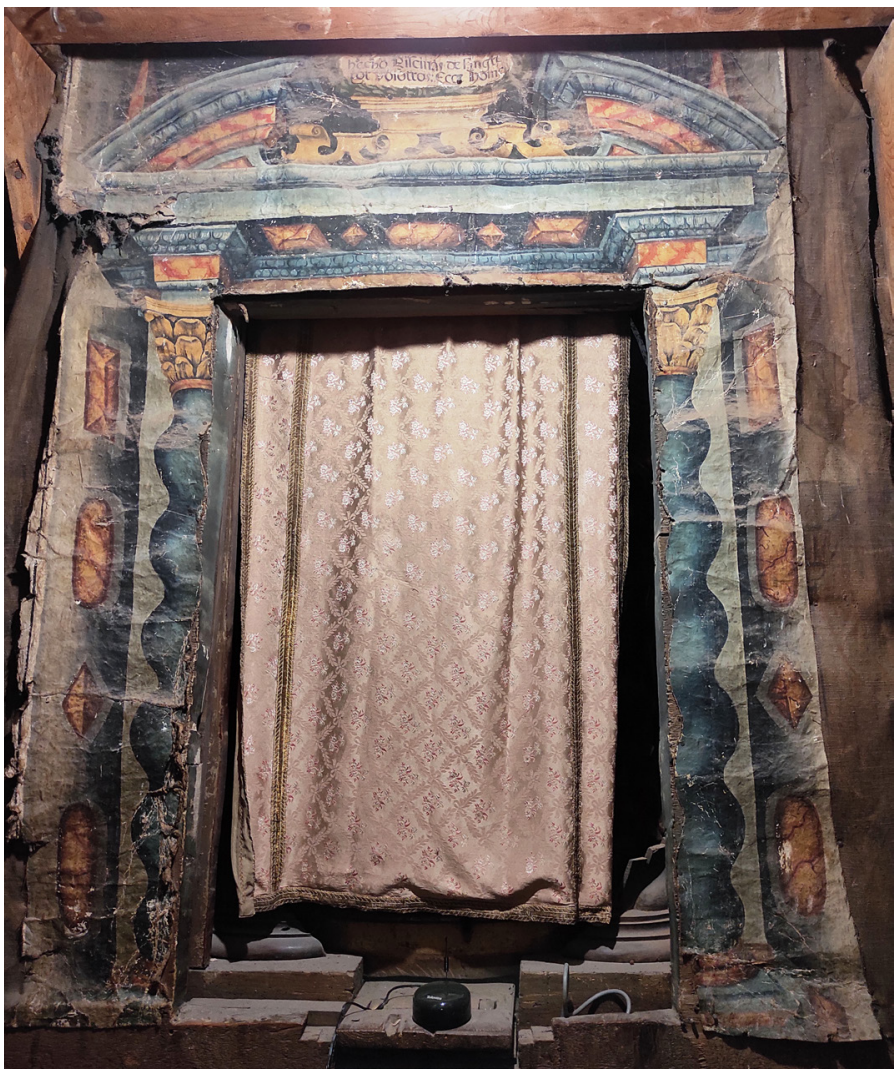

Fig. 3. Lugar que ocupaba la tabla en el retablo mayor de la iglesia del Salvador, Teruel, con la decoración que la rodeaba. Foto: Pedro Luis Hernando. variable que dificulta la comprensión de los avatares de la misma.

2 Santiago Sebastián se refiere a esta tabla en los siguientes términos: "En la sacristía hay que mencionar una tabla de la Santa Cena, de fines del siglo XVI", p. 412. 
A todo ello debemos unir el pertinaz problema que afecta al estudio de muchas obras de arte de la ciudad de Teruel, producido por la destrucción de iglesias y archivos durante la guerra civil. En el transcurso de la presente investigación no hemos localizado referencias documentales que nos permitan identificar esta obra. En sentido estricto, ni tan siquiera podemos afirmar con rotundidad que esta tabla haya estado siempre en la iglesia del Salvador. Tampoco conocemos cuándo se pudo colocar en el retablo, ni en qué momento se procedió a cambiar de lado la cerradura. Varias son las posibilidades que se pueden proponer sobre la presencia de esta obra en esta iglesia y en esta ubicación. Puede relacionarse con el citado hundimiento de la fábrica, siendo posible que la pieza perteneciera a la dotación artística anterior, reorganizada tras estas circunstancias. Otra posibilidad es que se trate de una de las muchas obras de arte que, tras las destrucciones de la guerra civil, la desaparición de varias parroquias y la reubicación de las obras recuperadas, acabara depositada en esta iglesia.

\section{Estudio iconográfico}

No obstante, un análisis iconográfico nos descubre algunas características que conducen a su catalogación cronológica y estilística. En primer lugar, la descripción de los gestos. Los personajes manifiestan diferentes actitudes ante el acontecimiento sagrado que están presenciando. Sus rostros, vestimentas y, sobre todo, las posturas de algunos de ellos aparecen forzadas y un tanto exageradas, recordando al concepto representativo manierista y luego barroco de los siglos XVI y XVII. El hecho de conceder protagonismo a la figura de Judas y su saco de monedas, aunque no sea una novedad, nos parece coincidente con la estética y con el contenido de la obra religiosa de ese periodo. Es la única figura cuya mirada establece contacto visual con el espectador.

Otro detalle es que la mesa en la que se celebra la Santa Cena es redonda, cuando resulta más habitual representar una mesa alargada, similar al más conocido modelo leonardesco (Rodríguez Velasco 2016). Aunque evidentemente no es algo exclusivo de esta obra, ya que encontramos otros ejemplos de esta tipología en obras anteriores, sí que podemos considerarlo una singularidad ${ }^{3}$. Parece el formato más idóneo dada la orientación alargada de la superficie pictórica y para la necesidad de incluir al mayor número de personajes en ella.

Son destacables igualmente las columnas colocadas en el fondo de la escena, enmarcando el momento del Lavatorio, tema iconográfico anterior a la Cena. Se trata de unas grandes columnas salomónicas de rotundas espiras decoradas con elementos vegetales. Flanquean una escalinata y soportan una cubierta plana abierta con óculos de iluminación ${ }^{4}$.

3 Únicamente por aportar al lector alguna referencia accesible de ejemplos anteriores de esta iconografía de mesa redonda, citamos el Tríptico de la Última Cena, obra de Juan de Borgoña (hacia 1470-1536) en la sacristía de la catedral de Toledo, la tabla pintada por Jaume Jacomart hacia 1450, actualmente en el MuseumderStadtRegensburg, la escena correspondiente del retablo de la Virgen de la iglesia de Rubielos de Mora (Teruel), o la tabla de Jaime Serra, pintada entre 1370-1400, que se conserva en el Museo Nacional de Palermo.

4 Son similares al estilo de las columnas representadas por Rafael Sanzio en los cartones de los Hechos de los Apóstoles (1515-1516), o por Giulio Romano en su Circuncisión (1522). Fuste torso y decoraciones vegetales fueron muy del gusto de los pintores manieristas, generalizándose su uso tras la construcción del baldaquino vaticano. 
Considerando todo ello, podemos afirmar que se trata de una interpretación basada en la escena que realizó el pintor Livio Agresti para el conocido Oratorio del Gonfalone de Roma, en el año $1569^{5}$ (Martini 2002). La principal diferencia es, como veremos, que se trata de dos momentos distintos de la Última Cena.

Este artista también parte de una superficie rectangular alargada. La divide en tres secciones longitudinales. La central se ocupa con la figura de Cristo, el cordero pascual en su bandeja y la escena del Lavatorio en la zona superior. Esta sección queda enmarcada por las dos figuras de cuerpo entero de primer término, los dos apóstoles colocados a ambos lados de Cristo, y dos de las columnas salomónicas del fondo. En las secciones laterales se agrupan el resto de personajes, en conversación tras el anuncio de que uno de ellos entregará

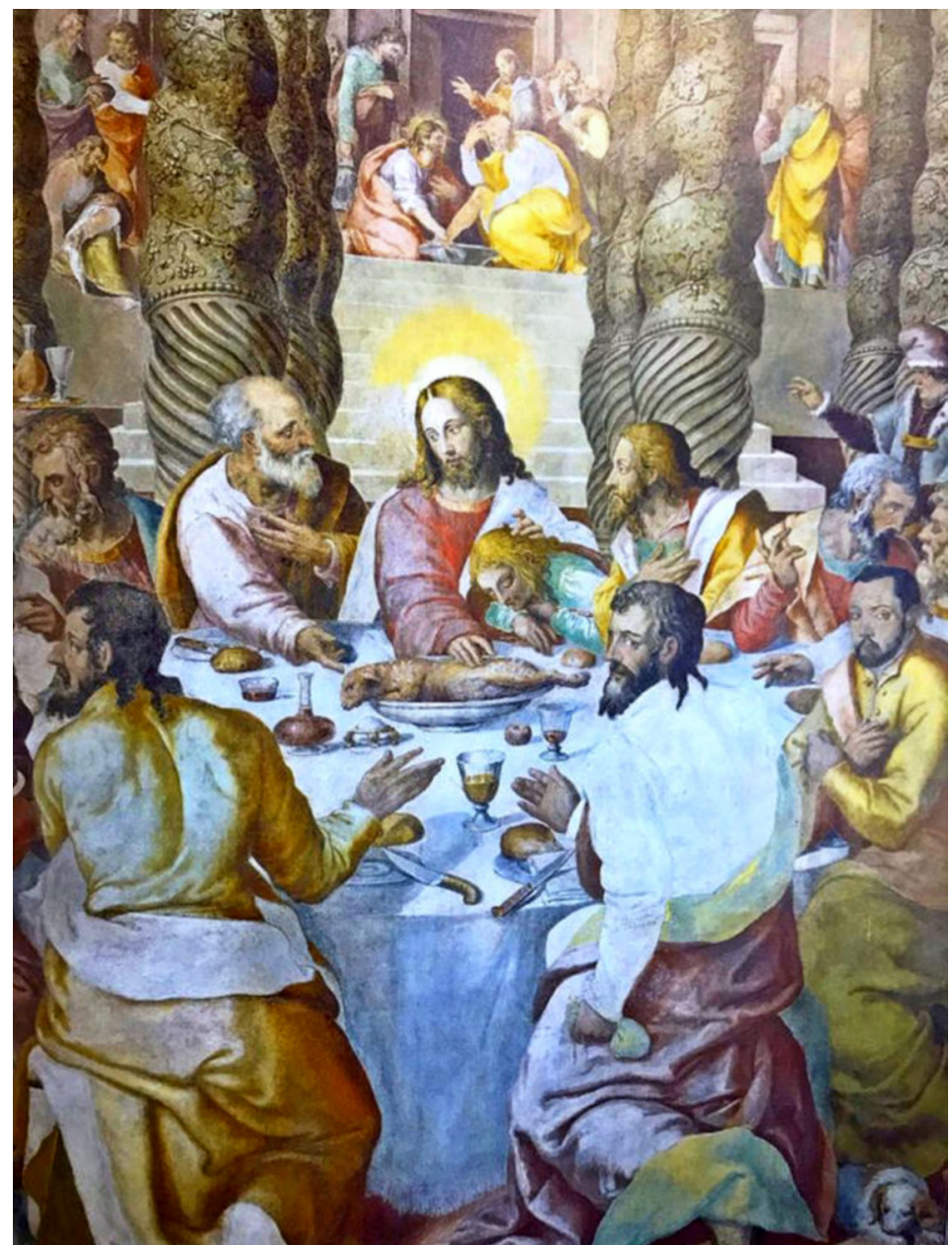

Fig. 4. Última Cena. Oratorio Gonfalone de Roma. https://www.facebook.com/ oratoriogonfalone/ al hijo de Dios (Fig. 4).

Con esta propuesta, no se debe afirmar que Agresti elaborara un modelo totalmente novedoso, ni que creara una estructura compositiva diferente. De hecho, no es extraño encontrar en la pintura gótica del siglo XV obras con similar organización, incluso incorporando la identificación de los apóstoles de acuerdo a su descripción psicológica. Lo que hace Agresti es recoger un modelo existente y representarlo de acuerdo con la nueva estética y el nuevo lenguaje manierista.

En el Oratorio del Gonfalone, junto con Livio Agresti, otros autores como Federico Zuccari, Giacomo Zanguidi, Marco Pino, Raffaele Motta o Cesare Nebbia realizaron escenas sagradas, generando una de las obras más reconocidas del manierismo romano (Melani y Ratti 2007). Por ello, muchas de estas escenas acabaron por convertirse en modelos o referentes para otros autores por toda Italia. Refiriéndonos sólo a la obra de Agresti, puede comprobarse la rapidez con la que se extiende su modelo en el entorno italiano, muy poco tiempo después de su realización. En torno a 1582, el pintor Gaspar Hovic reprodujo esa misma escena para la iglesia de Santa María Vetrana de la localidad de Triggiano (Caló Mariani 1962; Capotorto 2020). En las mismas fechas, el pintor Niccolo Circignani realizó para uno de los muros del refectorio del antiguo convento de San Francisco de la ciudad de Sermoneta,

\footnotetext{
5 Téngase en cuenta que la fecha de esas pinturas para el Oratorio del Gonfalone, sin duda de la última década de la vida de Agresti, oscila unos años según qué fuentes.
} 
ubicada a unos 80 kilómetros de Roma, un fresco con el mismo tema en el que se evidencia la misma influencia, aunque sin las columnas salomónicas del fondo (Testa 2007).

En el altar mayor de la iglesia de San Roque de Montorio al Vomano, en la provincia de Téramo, existe otra obra anónima que parte del mismo modelo y que se realizaría entre 1605 y 1607 . En este caso sí que aparece el fondo con las columnas salomónicas y la escena del lavatorio ${ }^{6}$. Tampoco conocemos el autor de otra obra que, con muy pocas variantes, se conserva en la Pinacoteca Comunale di Faenza?

La fama de esta escena llegaría también a territorio hispano en poco tiempo. En el Museo de Bellas Artes de Sevilla se conserva la obra de Alonso Vázquez, pintada en el año 1588 (Cómez Ramos 2016). Vemos la gran similitud con la figura de Judas, pero sobre todo con la del personaje ubicado inmediatamente a su izquierda, cuya particular musculatura es el signo más evidente de la relación entre ambas obras ${ }^{8}$.

Sin ser objetivo del presente estudio, ni intentar magnificar la importancia real de la obra de Agresti en la estructura compositiva de las representaciones de la Sagrada Cena en el arte posterior, sí que hemos localizado otras posibles reinterpretaciones tanto en el arte español como en el arte virreinal, por ejemplo, de la escuela de Cuzco. En el Museo de Bellas Artes de Sevilla se conserva una obra similar fechada en $1629^{9}$. También de las primeras décadas del siglo XVII es la Última Cena del convento de Santa Clara de Carmona, firmada por Pedro de Morales (Navarrete Prieto 1997). Unos años anterior, y atribuida al pintor Matías de Aguirre, sería la puerta que en la actualidad se conserva en una colección privada madrileña en la que se plasmaron las escenas de la Ascensión y la Última Cena, mostrando esta la misma fuente iconográfica que la anteriormente citada, con un curioso dosel que sirve de cierre a la escena (Mateo Gómez 2020).

La cuestión que se manifiesta en el proceso de análisis iconográfico de todas estas obras es que no se pudo generar una influencia tan clara entre territorios alejados y de un modo tan rápido sin la existencia de un factor de comunicación que fuera más allá de la mera contemplación visual.

Efectivamente, en torno al año 1578, el grabador flamenco Cornelis Cort realizó un trabajo en el que reprodujo la obra de $\operatorname{Agresti}^{10}$ (Fig. 5). Mantiene el mismo formato de la obra original y, aunque podemos ver diferencias, puesto que este tipo de obras no pretenden ser copias exactas, logra captar fielmente su mensaje espiritual y estético. Varía la tipología de los rostros de los apóstoles, la cantidad de objetos presentes sobre la mesa o alguna figura de la composición del fondo. Este grabado se confirma como el principal vehículo transmisor. La calidad de la obra, su reproducción y una evidentemente efectiva comercialización explican su amplia distribución geográfica y su éxito como referencia artística (Payo Hernanz 2001).

\footnotetext{
6 http://www.culturaitalia.it/opencms/viewItem.jsp?language=en\&case=\&id=oai\%3Aculturaitalia.it\%3Amuseiditalia-work 87577 Retablo mayor iglesia de San Roque al Vomano. Téramo. Italia. Licencia: CCO 1.0 Universal (CCO 1.0) Proveedor: MuseosD-Italia/ Iglesia parroquial de San Rocco. Identificador: work_87577.

7 https://bbcc.ibc.regione.emilia-romagna.it/pater/loadcard.do?id_card=142833

8 https://artsandculture.google.com/asset/la-\%C3\%BAltima-cena/mAFehChVWre2HA

9 https://www.pinterest.es/pin/831969731139671575/

10 https:/upload.wikimedia.org/wikipedia/commons/7/78/Laatste_avondmaal\%2C_RP-P-BI-6499.jpg

Rijksmuseum, CC0, via Wikimedia Commons
} 
De este éxito nos habla el hecho de que otros grabadores utilizaran la misma obra romana como imagen para sus grabados. Como ejemplo de ello podemos citar el trabajo realizado por Greuter Matthäus, conservado en la Pinacoteca dell'Accademia Carrara de Bergamo. La diferencia principal entre ambas obras es que la de Matthäus no incorpora la imagen del Lavatorio ni ninguna otra figura en el fondo de la composición ${ }^{11}$. También citamos la obra anónima que se conserva en la fototeca de la fundación Fererico Zeri de la Universidad de Bolonia cuya estimación cronológica varía entre 1530 y $1579^{12}$. De este modo, como puede imaginarse, las posibilidades de convertirse en imagen referente para otros artistas se multiplicaron exponencialmente.

La comparación entre la obra de Cort, junto con sus sucesivas reproducciones, y la tabla turolense también evidencia que es esta la fuente

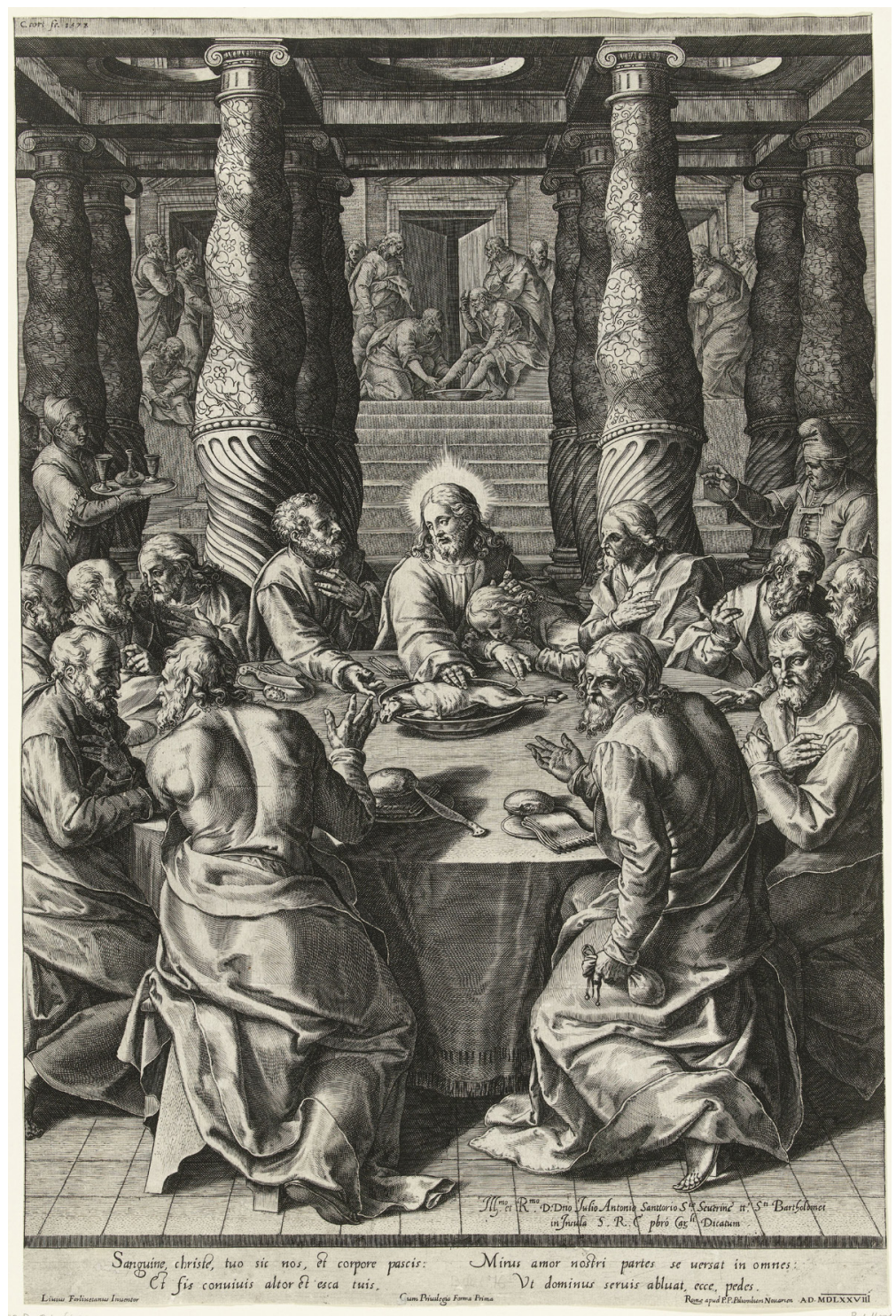

Fig. 5. Última Cena. Grabado de Cornelis Cort. Laatste_avondmaal,_RP-P-BI-6499 Licencia Comons. de la que bebe el artista para la decoración de su tabla. Como hemos apuntado en la descripción, el artífice de la tabla de Teruel se adapta al formato del soporte disponible. Respecto del grabado, elimina toda la franja de la derecha del espectador en la que encuentran tres apóstoles, la figura de pie y tres de los personajes del Lavatorio. Sí que se aprecia de una manera bastante fiel el mismo tipo de rostro del resto de los apóstoles y sus actitudes, siendo más notable en el caso de los dos personajes de primer plano.

La figura de primer término a nuestra izquierda tiene la misma posición, musculatura de la espalda, postura de la mano derecha, plegado de paños y posición del pie. Lo mismo ocurre con el personaje de Judas. La posición de la pierna flexionada y el pie, la postura de la mano y la bolsa de las monedas

11 Quizás sea este grabado el modelo seguido para las pinturas que, como hemos visto, copiaron la escena principal de la Última Cena y obviaron la secundaria de la parte superior, aunque mantengan la misma estructura arquitectónica. Se adjunta un enlace para acceder a la ficha catalográfica del inventario de bienes culturales de Lombardía en la que se puede ver la imagen completa del grabado http:// www.lombardiabeniculturali.it/stampe/schede-complete/C0060-00491/

12 http://catalogo.fondazionezeri.unibo.it/scheda/opera/31901/Agresti\%20Livio\%2C\%20Ultima\%20Cena Referencia INVN 75283. 
son idénticas. El artista copia incluso el gesto del rostro. También es idéntico el animal que se coloca en el centro de la mesa cuya forma, un tanto curiosa, evidencia de nuevo la relación entre todas ellas ${ }^{13}$.

No obstante, toda esta relación, existe una diferencia fundamental que las aleja desde el punto de vista del mensaje religioso transmitido. En la pintura italiana, como en el grabado holandés, Cristo señala con su mano derecha el cordero pascual colocado sobre la bandeja. Esto es fundamental en el mensaje de la obra ya que reproduce en imágenes el momento en que se pronuncian las palabras alusivas a la traición de uno de los apóstoles. Según el Evangelio de Juan 13:26, cuando es preguntado por quién va a ser el traidor, Cristo responde: A quien yo diere el pan mojado, aquel es. Esto es lo que da lugar a la escena, lo que hace que todo ellos se turben y se pregunten entre ellos sobre la cuestión. La obra transmite ese mensaje, adecuado para el lugar y el momento de su creación. Sin embargo, la tabla de Teruel sustituye ese momento por el del relato de Mateo 26, 26, en el que se dice: Y mientras comían, Jesús tomó el pan, y lo bendijo, y lo partió $y$ dio a sus discípulos, y dijo: Tomad, comed; esto es mi cuerpo. La actitud de Cristo coincide con el momento de la Comunión. Sin embargo, los apóstoles siguen hablando entre ellos, mostrándose un tanto ajenos a la importancia del acontecimiento que se está produciendo. En definitiva, el artista utiliza el modelo como base, cambia la imagen de Cristo para transmitir el mensaje de la Institución de la Eucaristía, dándole protagonismo a la Sagrada Forma y al cáliz, pero mantiene al resto de personajes en las actitudes que corresponden al mensaje anterior.

En el proceso de investigación realizado para el presente trabajo, hemos

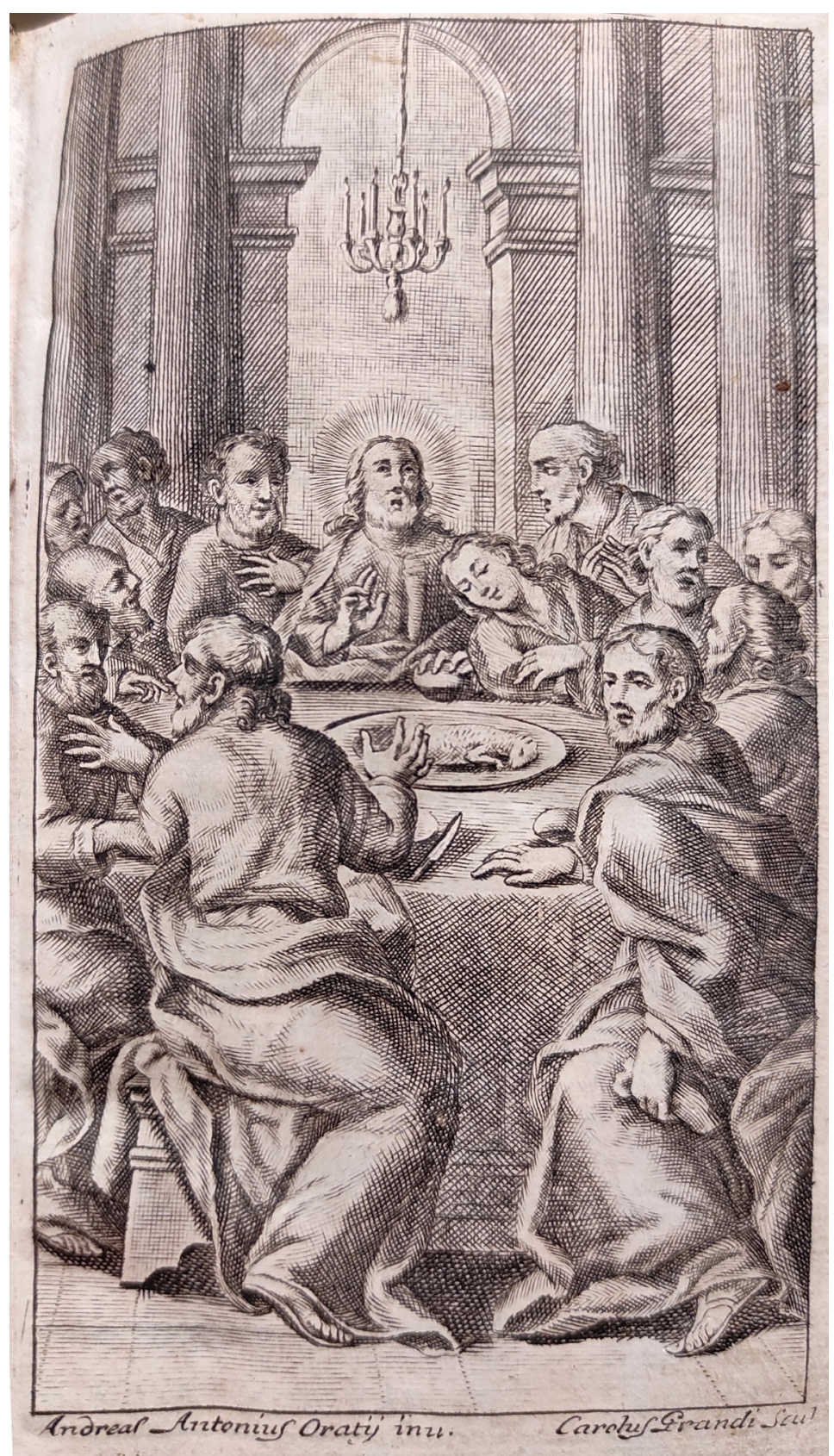

Fig. 6. Última Cena. Grabado procedente de la biblioteca diocesana de Teruel. Foto: Pedro Luis Hernando.

13 El proceso de copia del original y la falta de preocupación por este detalle pudieron ser la causa de que en algunas representaciones de la misma escena parezca que se trata de un conejo en vez de un cordero, siendo las patas el único elemento identificativo claro. Llevado al contexto hispanoamericano, entre otros a través de artistas como el citado Alonso Vázquez, esta confusión pudo tener valor catequético, puesto que allí el cordero no era conocido. En dicho contexto, puede no representarse pues el cordero sino un conejo de indias. 
encontrado otras referencias iconográficas relacionadas. Así, en un libro de rezos conservado en el archivo bibliográfico del Obispado de Teruel, encontramos un grabado que reproduce la escena a la que hemos estado refiriéndonos. En este caso, como ocurre con el grabado realizado por Greuter Matthäus, el fondo se no se resuelve con columnas salomónicas, si no con columnas de fuste recto. El grabado aparece firmado por Andrea Antonio Oratii y Carlo Grandi. Aunque probablemente realizado en las primeras décadas del siglo XVIII, nos confirma la vigencia del modelo en fechas muy posteriores. También nos permite comprender como las ilustraciones incorporadas en los libros pueden servir de instrumento de difusión de imágenes (Fig. 6).

\section{Conclusión}

La llegada a Teruel de este modelo puede ponerse en relación con el fluido comercio de estampas entre Italia y España producido a finales del siglo XVI (Tarifa Castilla 2017). Este periodo es, además, muy relevante desde el punto de vista artístico para la ciudad. En 1577 se erige la diócesis de Teruel a partir de los territorios de la archidiócesis de Zaragoza, y una buena situación económica permitió que los grandes linajes turolenses participaran en la dotación artística de sus templos. Conocemos el nombre de un buen número de artistas. Uno de los más conocidos es Juan Ambel, natural de Teruel y activo en las últimas décadas del siglo (Sebastián 1981). También se conoce la presencia del pintor romano Silvestre Estanmolín (Morte García 1987) ${ }^{14}$. Además, la documentación aporta varios nombres de pintores actuando en la ciudad (Morte García1988). Sin embargo, como indica el profesor Ernesto Arce, salvo contadas excepciones, "nada sabemos acerca de la personalidad artística de dichos maestros, meros nombres propios desprovistos de contenido." (Arce Oliva 1997). Sí que podemos concluir que se trata de la creación de un buen artista que, independientemente de partir de un modelo, gestiona correctamente la descripción anatómica de las figuras, el uso del color e incluso de la luz, en cuyo fondo se pueden apreciar rasgos de un buen estudio lumínico prototenebrista similar al que aparece en la pintura aragonesa de finales de la década de 1580, y cuyo mejor representante es Rolán de Moys (Morte García 1985). Así pues, podemos ubicar la obra en este contexto creativo, pero no atribuirla de momento a ningún autor.

En definitiva, la tabla conservada en el Museo de Arte Sacro de Teruel es un claro ejemplo de cómo se produce el proceso de transmisión de las iconografías y los modelos formales. Demuestra el gran interés, de parte de los artistas, de trabajar a la moda de cada momento, la existencia de mecenas que hicieron encargos a los mejores artistas del entorno. Confirma la participación de la ciudad en dichas rutas de comunicación artística y la existencia de un gusto adaptado a las necesidades de la ciudad y a las corrientes estéticas de cada momento.

14 http://www.unizar.es/artigrama/pdf/04/2articulos/4.pdf. http://www.unizar.es/artigrama/pdf/05/2articulos/7.pdf. 


\section{Bibliografía}

ARCE OLIVA, Ernesto. Pintores turolenses del siglo XVI. Studium Revista de Humanidades, 1997, vol. 4, pp. 37-43.

ARCE OLIVA, Ernesto. El Retablo de la Virgen del Rosario de Cella (Teruel), obra del pintor Silvestre Estanmolín (1601). Artigrama, 1988, n. ${ }^{\circ}$ 5, pp. 133-143.

GRAZIA BERNARDINI, Maria. L'oratorio del gonfalone a Roma. Il ciclo cinquecentesco della Pasione di Cristo. Roma: Ed. Silvana, 2003.

CALÓ MARIANI, María Stella. L’attività Pugliese di Gaspar Hovic (o Heuvick), pittore Fiammingo. Boletín de L'Istitut Historique Belge de Rome, 1962, vol. XXXIV.

CAPOTORTO, Salvatore. La vera storiadella tela dell'Ultima Cena di Gaspar Hovic. En: TMLand.it, Triggiano un nuovo modo di comunicare [consulta: 12 diciembre 2020]. Disponible en:

https://www.tmland.it/public/pdf/LA-VERA-STORIA-DELLA-TELA-DELL-ULTIMA-CENA.pdf

CÓMEZ RAMOS, Rafael. Alonso Vázquez. La "Ultima Cena” de la Catedral de Texcoco o la anatomía de la rutina. Laboratorio de Arte, 2016, n. ${ }^{\circ}$ 28, pp. 113-123. Disponible en: https://institucional.us.es/revistas/arte/28/Art_6.pdf

MARTINI, Antonio. L'Arciconfraternita del Gonfalone. L'Oratorio del Gonfalone a Roma. Roma: 2002, pp. 19-31.

MATEO GÓMEZ, Isabel. La Última Cena y la Ascensión. Anverso y reverso de una puerta atribuidas a Matías de Aguirre. Archivo Español de Arte, 2020, vol. LXXXIII, n. ${ }^{\circ}$ 329, pp. 61-100.

MELANI, Margherita y RATTI, Federica. L'Oratorio della Confraternita del Gonfalone a Roma. Ricerche di storia dell'arte, 2007, n. ${ }^{\circ}$ 91-92, pp. 83-92.

MORTE GARCÍA, Carmen. La pintura aragonesa del renacimiento en el contexto hispánico y europeo. III Coloquio de Arte Aragonés, 1985, pp. 277-302.

MORTE GARCÍA, Carmen. Una obra firmada y fechada del pintor Silvestre Estanmolín, 1579. Artigrama, 1987, n. ${ }^{\text {4 }}$, pp. 83-90.

MORTE GARCÍA, Carmen. Documentos sobre pintores y pintura del siglo XVI en Aragón, II. Boletín del Museo e Instituto Camón Aznar, 1988, n. ${ }^{\circ}$ 31-32, pp. 183-458.

NAVARRETE PRIETO, Benito. La pintura andaluza del siglo XVII y sus fuentes grabadas [en línea]. Tesis doctoral, Universidad Complutense de Madrid, Madrid, 1997. [consulta: 12 diciembre 2020]. Fig. 65, p. 208. Disponible en: http://webs.ucm.es/BUCM/tesis/19972000/H/0/H0047701.pdf

PAYO HERNANZ, René Jesús. La huella de los grabados de Cornelis Cort en el arte burgalés de los siglos XVI y XVII. Boletín de la Institución Fernán González, 2001, n. ${ }^{\circ}$ 223, pp. 255-284. 
POLO RUBIO, Juan José. Historia de los obispos de Teruel. 1614-1700. Teruel: Instituto de Estudios Turolenses, 2005.

SEBASTIÁN, Santiago. Inventario del patrimonio artístico de España. Provincia de Teruel. Madrid: Ministerio de Educación y Ciencia, 1974.

SEBASTIÁN, Santiago. Miscelánea de arte turolense. Teruel. 1981, n. ${ }^{\circ}$ 66, pp. 213-222.

RODRÍGUEZ VELASCO, María. Tipos iconográficos de la última cena y simbolismo eucarístico de las imágenes de la Edad Media. Revista Digital de Iconografía Medieval, 2016, vol. VIII, n. ${ }^{\circ}$ 16, pp. 119-142.

TARIFA CASTILLA, María Josefa. El comercio de estampas entre Roma y España a finales del siglo XVI. El caso del mercader italiano Antonio Pisano. Archivo Español de Arte, 2017, XC, 357, pp. 49-66.

TESTA, Sonia. Ultima Cena, affresco ex refettorio dell'eremo di San Francesco a Sermoneta.

En: http://conoscerepertutelare.altervista.org [consulta: 12 diciembre 2020].

Disponible en: http://conoscerepertutelare.altervista.org/affresco-raffigurante-lultima-cena-eremo-di-san-francesco-ser$\underline{\text { moneta/?doing_wp_cron }=1585240876.4251449108123779296875}$

VANNUGLI, Antorio. L'Oratorio del Gonfalone: Cronología e stato degli studi. Disponible en: https://www.academia.edu/29131860/LOratorio del Gonfalone cronologia e stato degli studi 